\title{
A Stress Reduction Guide for Teachers and Other School Staff
}

\section{National Education Association \\ and Center for Mental Health Service}

Whatever impacts our society-positively or negatively-will be evident in our schools. We will need to better prepare teachers for the challenges and harsh realities that they will encounter in their work. At the very heart of teaching are the unique and powerful relationships that can develop between teachers and students. Teachers must be experts in pedagogy and in the subjects that they teach. School Personnel also must become experts in human relationships, because education, at its core, is a human activity that is grounded in relationships. Robert Burke, $\mathrm{PhD}$, Associate Professor, Teachers College, Ball State University.

Stress related to violence in schools is an important professional development topic. The recent horrific incidences serve to highlight that violence is everywhere and cannot be predicted. That said schools are relatively safe places to work. Work place stress though cannot be ignored. The United States National Education Association Health Network with support from the Center of Mental Health Services, Substance Abuse and Mental Health Administration of the US Department of Health and Human Service produced a 42 page paper on Violence in Communities and Schools: A Stress Reduction Guide for Teachers and other School Staff. A section of this document has been modified and reformatted to fit the style of the journal and reprinted here. In addition, specific facts and information pertinent to this section of the report have been included.

(Copyright information is provided on pg 32)

\section{Introduction:}

Stress is a normal part of life at home or on the job. Workplace stress occurs across all types and levels of employment. In fact, many people believe that workplace stress in our society is increasing as workers are being asked to do more and more with less. The degree of resilience that a person brings to their experience of stress relates to the intensity and duration of the stressful experience, the individuals own unique personal qualities, including coping skills he or she uses; the individuals personal reaction to the particular source (s) of stress involved, including how he or she perceives the cause of stress or stressors; and the availability of social supports.

Given the prevalence of violence in our society today, it should come as no surprise that educators, parents and children can sometimes worry and feel stressed about the threat of violence-even in settings where they should be safe -their schools. The committee posed several questions. Are concerns about violence in schools realistic? Are schools safe places for our children, teachers and other school personnel? What can we do to identify and reduce stress associated with violence?

Jerald Newberry, Executive director, NEA Health Information Network, former Fairfax County (VA) teacher and school admin- istrator wrote: "As school employees, we have the task of trying to juggle educational demands with social and emotional needs of 30 or more individuals. Caring for ourselves is often the last thing on our minds".

Based on statistics taken form the State of America's Children Yearbook 2000 it was determined that:

One in four children lives only with one parent.

One in 24 lives with neither parent.

One in 60 , will see their parents divorce in any year.

One in five lives in poverty, one in six has no health insurance, one in twelve has a disability.

One in 910, will be killed by guns before age 20 .

For school personnel ordinary day to day stress can be compounded by exaggerated fears of violence in schools, fueled by misperceptions of schools as dangerous places for children. Compared to violence in other settings school violence is actually very rare. While school rampages that occurred in communities such as Littleton, Colorado, Springfield, Oregon, Paducah Kentucky [and more recently Bailey Colorado] are truly horrific, such high profile school killings are extremely uncommon. That said according to the report although statistics show that schools are safe, teachers and other school personnel do have genuine reason for some degree of concern. According to the US Department of Justice, while student-on-student violence has decreased in recent years, threats of violence directed to teachers have increased. It is recognized that students are not 
the only ones who are victims of crime at school. Teachers in school can also be targets of violence, theft, [and vandalism]. In addition to the personal toll such violence takes on teachers, those who worry about safety may have difficulty teaching and may leave the profession altogether. Information on the number of crimes against teachers at school can help show how severe and widespread the problem is (Indicators of school Crime and Safety, 2000). For more statistics consult the full report pages 8-11.

The advisory group consisting of 15 representatives from 12 national mental health and education organizations identified what they saw as being the four most critical stressors for school personnel in relation to violence in schools. They are: less

Feeling isolated and or power-

Lack of training and /or skills needed to identify and address student's behaviour that is potentially problematic

Lack of clear expectations and classroom and school wide management to meet those expectations

Fear of verbal emotional or physical intimidation.

In many cases personal changes even positive ones like reducing workplace stress, usually do not come about easily. This may be particularly true for people with Type A personalities who tend to be more susceptible to stress. Yet examining one's own perspectives and habits can be a good way to begin to identify how to prevent, manage and reduce stress. Through increased self awareness and stress awareness, we can make a difference. Taking a cognitive approach, we can replace self defeating thoughts with more positive ones. We can also consciously change our physical responses to stress through a number of techniques such as Biofeedback, Muscle relaxation, breathing techniques (to counter shallow breathing), aerobic activity focused meditation. In addition, assertiveness training and enhanced skills for enlisting the cooperation of others can be helpful in developing more effective coping strategies to reduce the stress that we live with day to day.

\section{Tips For Coping With Classroom Stress}

Establish priorities and pace yourself.

With small steps, tackle one problem at a time, one day at a time.

Focus on what you can control, rather than what you can't.

Evaluate your job demands and focus your energy on what is most achievable.

Take time to pat yourself on the back, celebrate your small successes, those of your colleagues, and those of your students.

Try to stretch your mind each day.

Be flexible: learn something new, try something different, seize a new opportunity

Reach out and touch someone.

Ask for help when you need itfrom a trusted colleague or a supervisor

Stay motivated.

Share your expertise, implement a new program, and try a new technique.

\section{Stay healthy.}

Exercise; eat properly; get enough rest; limit the use of alcohol and caffeine.
Leave your worries behind when you leave the classroom.

Use your time at home to relax, nurture yourself and enjoy your family and friends.

\section{What Can School Systems Do To Reduce Stress?}

What can school staff, administrators, and communities do to address the multiple stressors that affect school employees? Because every school and community is unique, there are, perhaps, as many solutions and approaches as there are schools.

Our advisory group provided the following recommendations for what schools and communities can do in relation to each of the 4 identified critical stressors facing teachers and other school staff.

\section{Stressor 1. Feeling Isolated And Powereless}

Working in a classroom can be an isolating experience. Spending most hours of each workday in a classroom with students leaves little time or opportunity for significant contact and connection with colleagues and other adults. In addition, staff in many schools lack access to telephones, voicemail, and email - communication options that are typically available to workers in many other settings.

The following interventions are recommended for reducing the isolation that school staff can experience and for empowering staff as contributing members of the school and community:

Build/sustain peer connections by intern programs; providing mentoring programs; designating teacher leaders; and organizing teaching teams.

Provide recognition. As rewards, in and of themselves, rec- 
ognition and acknowledgment for good performance can increase motivation and reduce stress.

Provide performance incentives that increase cooperation rather than foster competition.

Promoting cooperation rather than competition - directly addresses isolation.

Concrete incentives that reward group performance introduce a shared goal towards which staff can work together.

Build/support effective community involvement in schools. Community involvement in schools can reduce staff isolation. By reinforcing the notion that schools are vital and essential contributors to the community, this type of involvement can help to reduce the risk of burnout among staff. Increasing the pres

Reach out to an intern, a mentor, or a peer.

Get involved in managing, planning, or policy-making.

Recognize and reward excellence.

Build incentives for cooperation and collaboration.

Involve and work with the community.

Build/sustain peer connections by providing intern programs: providing mentoring programs; designating teacher, and organizing teaching teams.

These interventions are designed to reduce isolation by creating connections and enhancing relationships among school staff. Allocating time and otherwise providing administrative support for school staff to connect with one another is deemed to be key for the success of these interven- tions. National Board Certification for master teachers can serve as a vehicle for supporting mentoring relationships: some states even provide financial incentives by covering the cost of certification. Models for mentoring programs are abundant. The provision of adequate time, space and other resources for teaching teams to work together and to support each other resources for teaching teams to work together and to support each other is essential for teams to thrive.

\section{Involve teachers in decision- making.}

Site-based management and local restructuring can provide teachers and other school staff with opportunities to participate in important decision-making. For example, administrators can involve teachers in efforts to recruit and interview candidates for staff positions, allowing them to directly contribute and share in the responsibility for hiring decisions. Involving staff in decisions that relate to student behavior is an important dimension of empowering school staff, particularly in relation to violence-related stress. Staff participation in the development and implementation of discipline policies and outcomes directly addresses both the isolation and powerlessness aspects of violence-related stress risk of burnout among staff.

\section{Provide recognition}

As rewards, in and of themselves, recognition and acknowledgement for good performance can increase motivation and reduce stress.

Provide performance incentives that increase cooperation rather than foster competition.
Promoting cooperation-rather than competition directly addresses isolation. Concrete incentives that reward group performance introduce a shared goal towards which staff can work together.

\section{Build support effective commu- nity involvement in schools.}

Community involvement in schools can reduce staff isolation. By reinforcing the notion that schools are vital and essential contributors to the community, this type of involvement can help reduce the risk of burnout among staff. Increasing the presence of community members in the schools can enhance community understanding of the environment in which teachers and other school staff work. It can reinforce community recognition of the important contributions made by schools and increase the prestige of school staff within the community. Community involvement can also yield greater opportunities for schools and communities to identify common goals and priorities. Providing access to community resources for professional development for school staff addresses both powerlessness and isolation. When linked and responsive to identified needs for curriculum assessment and classroom management, community resource banks can make schools more responsive to the communities they serve and enable communities to be more responsive and supportive of schools. The Federal government's Safe Schools/Healthy Students Initiative [visit: www.sshsac.org] highlights the importance of effective community involvement in schools. Drawing from best practices in mental health, social service, education and justice, this ini- 
tiative seeks to promote a comprehensive, integrated framework that communities can use to address school violence.

School-community partnerships are also highlighted as an essential ingredient in SAMHSA's School and Community Action Grants. Step one for each of the 40 grantees awarded in 1999-2000 was to build consensus among school-community stakeholders. Once consensus has been established as a foundation, grantees pilot evidence-based programs and practices to promote healthy development and prevent youth violence.

\section{Stressor 2: Lack Of Training} And/Or Skills Needed To Identify And Address Students Behavor That Is Potentially Problematic.

Build partnerships with schools of higher education.

Use simulations to practice skills and gain experience.

Take advantage of all the talent in your school system.

Develop partnerships with community-based agencies.

Involve and work with the community.

Strengthen parent involvement.

The advisory group identified a need among school personnel for training to help staff identify and respond to student behavior that may indicate a potential for violence. Their recommendations urged each school to identify classroom management resources that teachers can turn to both inside the school and in the community. Specifically, the group recommended the following interventions to assist teachers and other school staff to recognize when students need help and to allow staff to feel better equipped and more able to help with addressing student mental health needs.

\section{Recommended interventions:}

Build and maintain partnerships between schools and postsecondary schools of education and other post-secondary education institutions for pre-service and in-service training. The accumulated expertise of experienced educators offers a valuable resource for pre-service training. Partnerships between K- 12 schools and post-secondary schools of education would provide a mechanism for integrating experienced classroom teachers, administrators and other experienced professional school staff into standard pre-service postsecondary training curricula. Bringing seasoned teachers and administrators into post-secondary classrooms would greatly enrich the reality base for pre-service instruction.

Provide experiential learning and classroom simulation in preservice and in -service training. Developing skills and generating confidence in the use of newly acquired skills requires practice. Particularly in relation to identifying, understanding, and addressing student behavior, experiential learning and classroom simulation would provide opportunities for staff to practice the skills they will need to rely on when they face actual situations with students.

Recognize and utilize existing expertise among school staff for in-service training and workshops. Designate mentor teachers to train faculty members.

Invite pupil services personnel (e.g., school nurses, school psychologists, school counselors, school social workers, occupational therapists, and others) for in-service training across professional disciplines represented among school staff.

Develop and maintain school/ community partnerships for access to community-based training and consultation resources. By building formal relationships with community- based professionals and organizations, school staff can gain access to valuable expertise for staff development and ongoing consultation. Potential community-based resources include health centers, mental health centers, social service agencies, private social service organizations, youth advocacy organizations, hospital-sponsored programs, recreation centers, and faith/religious-sponsored programs. Providing adequate opportunities for staff development, including sufficient time for school staff to participate in training and consultation activities, is key for making the best use of community-and school-based resources. Time set aside for these activities should take into account the schedules and workloads of teachers and other school staff so as not to create more stress. Meaningful parental involvement can make a pragmatically important contribution to school staff professional development. The advisory group recommended that schools invest in strengthening parental involvement by creating and maintaining formal mechanisms and programs for parents to volunteer their time in schools. One aspect of this would be for schools to provide training for 
parents to serve as volunteer classroom monitors. With some training, parents could feel better prepared and more competent to take on the roles assigned to them at school, thereby enhancing their ability to contribute in a meaningful way. Trained parent volunteers could make an essential contribution to staff professional development by helping to make more staff time available for training, consultation and other professional development activities.

\section{Stressor 3: Lack Of Clear Expectations And Classroom And School-wide Management To Meet Those Expectations}

Establish clear expectations and concrete norms for acceptable student behavior.

Communicate those expectations and norms to the entire school community.

Know you can count on backup from supervisors when implementing established policy.

Identify and use evidencebased best practices to address particular needs in your classroom or school.

Involve and work with the community.

Strengthen parent involvement.

Everyone needs to have a clear understanding of what is expected of them before they can know how to succeed in meeting those expectations. Working without a clear and concrete understanding of a school's expectations, particularly in relation to student behavior and discipline issues, can contribute significantly to violence-related stress for school staff. A lack of clear, concrete expectations for student behavior also works against violence prevention in schools.

\section{Recommended Interventions}

Develop clear, concrete; school-wide (i.e. for all classrooms and for all non-classroom school settings) expectations for student behavior.

Expectations for student behavior best serve the school when the process for developing them involves school-wide and community- wide input. Such input and consensus building allow for greater feelings of ownership and support. Community involvement in this process also addresses the isolation aspect of stress.

These expectations might include explicit guidelines to promote certain positive behaviors (e.g., service to others, good citizenship) and prohibit others that often precede actual violence (e.g., name-calling, bullying). Establishing school norms for behavior can be an effective form of violence prevention

Effectively communicate expectations regarding discipline and student behavior to everyone in the school community. In order for them to be meaningful, expectations for student behavior in the school need to be translated into concrete, real-life terms. This should include clear, concrete definitions of the roles and responsibilities of school staff and every other member of the school community.

School leaders and administration must support school staff whenever they take action that is within school guidelines and/or policy to respond to student behavior or discipline problems.
Feeling ineffective is bound to cause stress. Conflicts over discipline among staff, administration, and others in the school can generate significant stress for everyone involved. In order to enhance effectiveness in upholding school expectations for student behavior, staff need know that they have the support of their colleagues and school leaders. If school expectations have been developed with community-input, the potential for parents to undermine the authority of a teacher or other school staff can be minimized. Stress can be reduced and confidence can be increased when staffs know that, when they act in a way that is expected of them, they can count on being backed up and supported. The goal of this recommendation is to assure that every member of the school community can say, "I am clear about what is expected of me. I am confident that when I take an action that is consistent with these expectations, my school community will back me up

Identify/research best practices for your (i.e. the teachers or the school) particular needs.

Best practices could include making use of school management techniques, such as the use of block scheduling. Block scheduling reduces the amount of student traffic in the hallways. Reducing crowding contributes to violence prevention in schools which, therefore, contributes to preventing violence-related stress for staff who may be required to monitor hallways. Once in place, the overall management strategy chosen by the school must be sustained. A continuous improvement model (e.g., assess, design, implement, assess, re-design, etc.) should be applied to allow for 
adjustments as needed. A mechanism for evaluation, particularly for gathering and incorporating feedback, would be important to include.

\section{Stressor 4: Fear Of Verbal, Emotional Or Physical Intimidation}

Take advantage of opportunities for training in violence prevention.

During a crisis, communicate risks openly.

Plan ahead for how staff will respond if a crisis occurs at your school.

Collaborate with communitybased mental health and law enforcement agencies on violence prevention and planning for crisis response in schools.

A significant amount of research has been done with children, war veterans, and police/ emergency personnel to examine how exposure to violence affects their health and mental health. Relatively little research; however, has been conducted with teachers and other school staff. More than 20 years ago, 4,934 elementary and secondary school teachers employed by the Chicago Board of Education were asked to respond to "Teaching Events Stress Inventory" ranking the stress level of teaching events that they actually experienced. Among the top ranked concerns were violence, student discipline, management of disruptive children, threats of personal injury, and verbal abuse by students.' 16 (Cichon and Koft 1978). Today, teachers and other school staff face stressors that did not exist or that were not as prevalent 20 years ago as they are now, such as pressures to boost student achievement on standardized test scores, an increasing amount of diversity among student populations, and having to accommodate larger class sizes. These current stressors add to, and potentially exacerbate, school staff fears of verbal, emotional or physical intimidation.

\section{Recommended Interventions}

Training/participation in violence prevention programs:

Drawing from prevention research, some schools are focusing their interventions on behaviors and situations that often are precursors to violent behavior. Evidence-based violence prevention programs and practices include: conflict resolution, anger management, peer mediation, bullying prevention, prevention of sexual harassment. Some research suggests that school staff should focus on relationship building, with an overall goal of developing positive connections with students, rather than focusing on rules, discipline, and consequences. Training to help staff become more effective listeners, such as using reflective listening skills, could support and enhance teacher-student relationships. In addition, cultural competency programs that foster respect, understanding and acceptance of others make an important contribution.

Provide a realistic assessment of risk and facilitate adequate, accurate communication among school personnel, parents and others.

Planning, preparation and adherence to a procedure for ensuring that regular, accurate communication will be maintained whenever a crisis does occur reduces speculation and fear among staff, students and parents. It is important for school officials to inform staff of events when they occur and to inform them about outcomes, including how incidents get resolved. This recommendation also addresses the first critical stressor that can contribute to violence-related stress, feeling isolated and/or powerless.

Communication of accurate information decreases the influence of rumors that often develop after an incident. Open lines of communication with parents and other community members can set the stage for collaboration and avoid a tense, and possibly even litigious, climate. So, it is especially important for administrators to ensure that regular communication occurs with the community, including open communication about how incidents have been or will be resolved.

Maintain school safety and crisis response plans and procedures.

It reassures school personnel to know ahead of time what to do in the event that a crisis does occur. Having school safety and crisis response plans and procedures in place for every level - classroom, building, district and community - makes a significant contribution to reducing violence- related stress. [See NEA Crisis Communications Guide and Toolkit, Vol. 1, Being Prepared - Before a Crisis, page 1.6 - "Checklist - How Does Your School or District Crisis Response Plan Measure Up?"]

Create/maintain partnerships with law enforcement, mental health and other communitybased agencies and personnel. Particularly for violence prevention and crisis response work, schools should not function in isolation from the community.

School partnerships with community-based agencies are essential 
for planning and implementing effective crisis response. These partnerships provide access to expertise and resources that schools generally do not have (e.g. emergency fire and rescue) or may have (e.g., mental health services), but not in sufficient quantities. High caseloads for pupil services personnel may not allow for them to take on an active, primary role in school safety and crisis response.

Violence that occurs outside of school can also have an impact inside the school. Communication and collaboration with mental health, social service, and law enforcement agencies can assist schools in violence prevention efforts and can help school officials and school staff to be better prepared for dealing with violence when it does occur at school. Because schools are unique environments in which to work, community-based professionals may need time and guidance to get oriented to school culture. Community based professionals may not be familiar with procedures, protocols, and various laws and regulations that influence the way schools operate and function. Although community based professionals may have much to offer in terms of expertise or experience, a lack of familiarity with or understanding of the school setting can undermine even the most well intentioned efforts. Community-based personnel need orientation, training, and informal mentoring and support for their work in schools.
This document includes twelve pages of resources, guides, books, videos, programs, and web sites and an extensive bibliography that are worthy of scrutiny.

To obtain a full copy of this document consult the NEA Health Information network's web site at-www.neahin.org/ mentalhealth/stressguide.htm. Public Domain Copyright

Copyright permission granted by National Education Health Information and Center for Mental health services, substance Abuse and Mental health Services Administration, U.S Department of Health and Human Services. Violence in Communications and schools: A Stress Reduction Guide for Teachers and Other School Staff. Washington, D.C: National Education Association Health Network. April 2001. $\%$

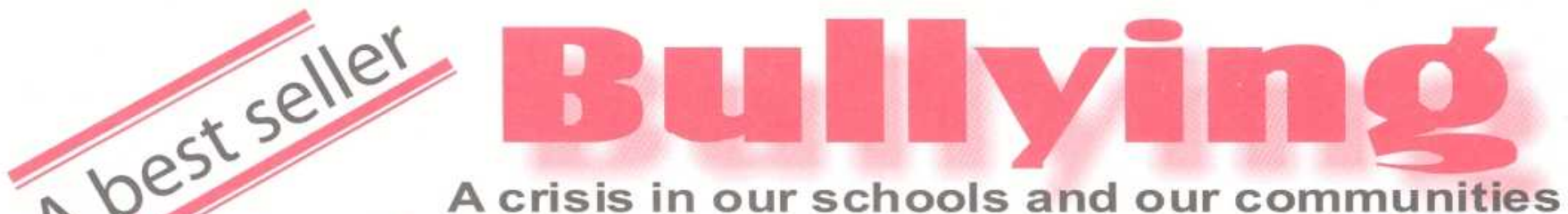

by Raymond T. Chodzinski

The stories, including the author's own, and the research, strategies and gleanings contained in this book are a result of reflection on numerous counselling episodes, and many hours spent listening and discussing child-related violence with parents, teachers, social workers, graduate students, conference participants and workshop delegates.

Available from

BK-301 Pp. xii + 132, 6" x 9" éditions Soleil publishing inc. soleil@iaw.on.ca

\section{Author! Author!}

Are you interested in publishing a book, a workbook for the course(s) you are teaching?

Do you find yourself photocopying articles after articles which you would like to see in book form?

If you are interested in publishing, contact soleil@iaw.on.ca for further information. You need not publish thousands of copies. We specialize in small quantities. Professional editorial assistance is available.

Contact éditions Soleil publishing inc. Tel./Fax: (905) 788-2674. Ask for the "Publishing Department". 